\title{
Technology and students' musicking: Enhancing the learning experience Abstract:
}

High levels of engagement with technology are characteristic of young people in the $21^{\text {st }}$ century. Teachers and curriculum designers can utilise students' comfort with technology to enhance learning. Easy access to information on the internet is also significant because the former role of teachers as a primary source of information is no longer central to students' learning; effective teaching may need to be rethought to acknowledge the informal learning that pervades our students' lives. This article examines an undergraduate degree program in popular music that has embraced a wide range of music-making technologies as pedagogical aids and uses rich assessment tasks including both technological and musical aspects. While such complex processes might not be appropriate in all settings, there are similarities with the Musical Futures project (Green, 2008) that is thriving in Australia and the United Kingdom, providing a good example of innovative musical pedagogy in secondary schools.

\section{Introduction:}

The developers of the program described in this article sought to provide an experience that utilised the learning attributes and skills of their students. They believed the transmissive practices that dominate Higher Education Music education did not acknowledge the independent learning possible in the post-broadband era. Such considerations might also apply in other educational contexts.

In 1999, an initial cohort of 20 students commenced a new Bachelor of Popular Music (BPM) program in an Australian university-based conservatorium of music. This program had been developed to produce outcomes that would be useful in a career in popular music, particularly a knowledge of a wide range of current and historical popular music repertoire, meaningful engagement with songwriting, an understanding of the business aspects of music, familiarity with sound recording and other creative music technologies, and an ability to provide and receive feedback constructively. Significantly, the development of the program's pedagogical approach was informed by assumptions about the ways people learn popular music outside formal education settings. This development occurred at a time when very little had been published on this topic ${ }^{1}$. The most important assumptions were that popular musicians learn principally with and from each other; they are less reliant on instruction from experts than other conservatorium students are likely to be; their engagement with music making is likely to be diverse; and technology plays a significant role in their learning.

\footnotetext{
1 Subsequently, Lucy Green (2001, 2006, 2008), Heidi Westerlund (2006) and others have written extensively about how popular musicians learn.
} 
These assumptions were a necessary component of the thinking around the program's development because they were part of what the students brought to the process, part of the 'presage' of this learning system, as John Biggs (1999) has conceptualised in his 3P structure of learning systems. The 3P model refers to:

Presage - those factors in play before a particular learning activity commences, including pre-existing attributes of students and those aspects of the established learning system that will influence students' engagement with learning;

Process - those factors in play during the learning activity including the pedagogical approach, curriculum, and assessment processes; and

Product - the outcomes of the learning activity, including the effects of the learning activity on students.

Even though it is usual to consider the learning processes we design for students and look carefully at the products of those processes in terms of the achievement of desired learning outcomes, consideration of students' existing learning abilities and dispositions is less common. All three of these aspects warrant consideration and the presage aspect is particularly important when students are engaging in a range of learning activities that are made possible through their engagement with technologies of various kinds, including the internet.

Biggs (2008) provides another useful way of thinking about learning systems through his writing about constructive alignment. He advocates starting by considering what we would like students to be able to do and know on completion of a learning activity (the product), then ensuring that the curriculum, pedagogical approach, and assessment (the process) align positively with these desired outcomes ${ }^{2}$. Along with the presage, these aspects are interactive in the sense that the students' pre-existing learning dispositions and skills will influence their engagement with the learning process, which in turn will influence the outcomes. The following describes the development of the BPM program, drawing on the 3P model of learning and the principle of constructive alignment; the prior learning of students, the inclusion of diverse and collaborative learning activities, and the relevance of learning outcomes to the likely futures of graduates are all considered.

\section{The BPM program:}

\footnotetext{
${ }^{2}$ See Wiggins \& McTighe (2005) for another perspective on this concept.
} 
Rather than continuing to rely on assumptions about the prior learning of students entering this program, a survey ${ }^{3}$ of commencing students has been conducted annually since 2003, asking students about the kinds of music they have studied, their ways of learning music, the kinds of feedback they used, and the range of music making activities with which they engaged. Findings from these surveys ${ }^{4}$ indicate that popular music students have generally engaged with several music-making activities (an average of 5), rather than being focussed on a single specialism as is common in students of classical music (an average of 2); they are likely to have limited engagement with private lessons and will have learned music mainly with and from friends and band mates; technology is likely to have played a substantial role in their music-learning through engagement with recording, the internet, and computer music applications. These findings confirmed the assumptions that were made about the learning abilities and dispositions of students entering the program.

\section{The program design:}

The primary learning outcome intended for the BPM program was that graduates would be well prepared for professional engagement with the popular music industry. The kinds of attributes that are useful for a popular musician [as described by Green (2006) and others] include welldeveloped song writing and performance skills, informed by knowledge of the history and cultural context of popular music, competence with recording and computer music technologies, and most importantly, an ability to learn with and from others effectively. These considerations informed the development of the BPM program and have resulted in a curriculum that includes courses in audio engineering and production, live performance projects, the history and analysis of popular music, creative music technologies, rhythm studies, music industry studies, composing and arranging, and work integrated learning placements. The central course is Popular Music Production, taken by all students in each of the six semesters of the program. It is largely self-directed and students learn mainly through the preparation of recordings of their original compositions.

In Popular Music Production, students submit a proposal early in the semester outlining their plans for preparing their recorded submissions; teachers award a mark for the quality of the proposal document and also provide feedback on the viability the students' proposals. This is an important aspect of the course because students have a high degree of autonomy, deciding for

\footnotetext{
${ }^{3}$ The survey was based on the work of Ryan Daniel (2001) to enable preliminary comparisons between students of popular and classical music.

${ }^{4}$ Lebler, 2007, 2008b; Lebler, Burt-Perkins, \& Carey, 2009.
} 
themselves what they will record, with whom they will collaborate, and how they will go about realizing their creative intentions. Regarding the proposal as an assessment item that contributes to the course grade is an acknowledgement of the importance of good planning and goal setting for this kind of independent work.

Students present work-in-progress to their peers for feedback throughout the semester. This kind of peer feedback is normal among popular musicians (Green, 2001, 2006) and most feedback is sought and given informally. However, students are required to present work in progress at least once a semester using an on-line facility developed specifically for this course; they upload a recording and specify which aspects of the work they are particularly interested in getting feedback about. Teachers and other students provide written feedback on-line. Students are also able to access archives of previous student work so they can benchmark their own work against the past submissions of others. This kind of feedback process engages students in discussions with people who may be outside their normal collaborators or circle of close friends, contributing to the development of an extended learning community.

Students submit their recordings at the end of the semester along with documentation outlining what they intended each track to be, who else was involved in the recording and to what extent each participant was responsible for the outcome. They will also comment on how well they think they achieved their intentions and mark each of their submitted tracks for how well the track has achieved the stated intentions, the quality of the track overall, the quality of their individual contribution, and the significance of their contribution. They also mark their submission as a whole.

In this process, the students are the first markers of their work. It is important that students develop an ability to make well-founded judgments of this kind to prepare them for lifelong learning, so they can monitor their own progress effectively and direct their own independent learning. There is considerable support for self-assessment (and peer assessment) in the literature on education; Google Scholar searches for these terms will produce numerous results. However, as is evident in much of the literature, this is not an easy alternative to the more usual assessment by teachers; modes of assessment that involve students as assessors become even more complex when the material being assessed involves collaborative work and multifaceted contributions from individual students.

Most Popular Music Production submissions involve collaboration and students will usually contribute to their submissions in a number of ways, usually having a role in the 
composition, arrangement, and recording of tracks as well as a number of other roles that could include vocal and instrumental performance as well as the programming of computer generated performances. Between 2006 and 2008, almost 98\% the 1,616 tracks submitted included more than one kind of contribution from the submitting student, and almost $80 \%$ of submissions included four or more kinds of contribution by the submitting student. In addition, most tracks are the result of collaborative work, with almost $90 \%$ of tracks being the result of collaborations and almost half involving four or more participants (Lebler, Burt-Perkins, \& Carey, 2009). These submissions reflect the collaborative and diverse engagements popular musicians have with their music making, and these dispositions are an important aspect of presage, part of what the students bring to the process.

The role of technology in this process is pervasive. All courses in the degree program have a web presence through the university learning management system and most have significant resources available in the course web site; some courses also have a YouTube presence. Students learn from recordings of their heroes and they make recordings of their own work and learn from what they hear in playbacks. They frequently use computer applications to construct part or all of their recordings, and use YouTube as a source of information and instruction. They also use Facebook to share their own music with each other and to direct friends to their music on other social network sites, using peer feedback outside of the context of their degree program. As George Siemens writes:

Blogs, wikis, and other open, collaborative platforms are reshaping learning as a two-way process. Instead of presenting content/information/knowledge in a linear sequential manner, learners can be provided with a rich array of tools and information sources to use in creating their own learning pathways. The instructor or institution can still ensure that critical learning elements are achieved by focusing instead on the creation of the knowledge ecology. (2005)

In the BPM context, technology is a central feature of the student learning experience and it has become an essential ingredient of the assessment process (Lebler, 2010). In essence, this is an instance of the use in a formal context of informal learning attributes and processes that are natural for students, certainly for this cohort at least.

\section{The assessment process:}

Since 2001 the assessment of recorded submissions and the associated written work has been conducted by panels consisting of six or seven students from all year levels of the program and a 
teacher. Each panel assesses the complete submissions of six or seven students from all year levels of the program. Panel members have access to the submitting students' written work that is associated with the recorded submissions. Each panel member provides individual feedback and marks out of ten for each of four criteria for each track along with marks for how well the written work described the submission (out of ten marks) and the quality of the submission as a whole (also out of ten marks). The track marks are averaged and added to the marks for the submission as a whole to produce a mark out of $60^{5}$. The comments from panel members are collated, the marks averaged and all of this is returned to the submitting student at the completion of the process. The Popular Music Production learning process has been reported in detail previously (Lebler, 2007, 2008a, 2008b, 2010) and can be represented as shown below in Figure 1.

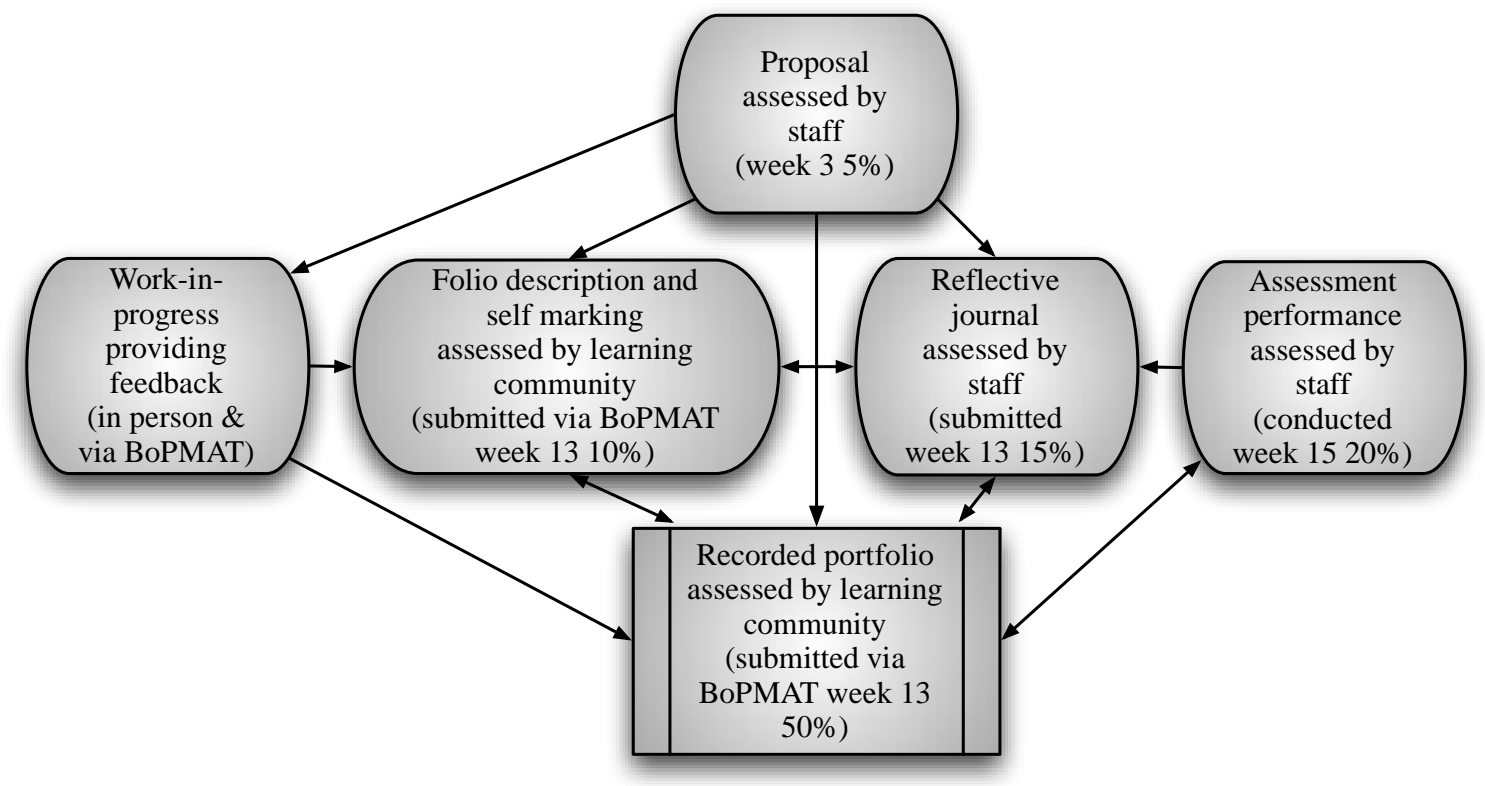

Figure 1. Popular Music Production

Following some initial concerns from students about their ability to conduct this kind of assessment, a lecture about the value of self and peer assessment was introduced as part of the orientation of new students to the program. As longitudinal data was collected about the marking process, comparisons between the marks awarded by panels as a whole and those awarded by the teacher panel member demonstrated a very close correlation, confirming that no student would be

${ }^{5}$ A reflective journal is also submitted and marked by teachers out of 15 marks, and all of this together with the mark for the proposal (out of five) accounts for $80 \%$ of the student's mark for the course. Teachers award the remaining $20 \%$ of the course mark for the quality of students' contributions to the peer assessment process. 
disadvantaged or advantaged by this method (Lebler, 2008a). Students found this information reassuring and the assessment panel process is now accepted as normal in this program.

The early iterations of this process involved a cohort of about 40 students and used printed copies of the written aspects of the submissions and CDs for the recorded music. As the size of the cohort grew, the process became more electronic in an effort to make it more manageable, with Excel worksheets used for the written work and digital copies of the recordings being posted on a secure streaming server; this enabled panel members to engage with the material they were assessing before the assessment panel meeting at which the formal assessment was conducted. Panel members entered their assessment comments and marks into Excel worksheets and submitted them through the course learning management system. These were then collated using Macros in Excel and made available to the submitting student through the learning management system.

By 2009, the size of the cohort was approaching 120 students and in semester 1, 2009, this assessment process produced 268,514 words of feedback averaging 2183 words per reviewer, for an average of 88 words per reviewer per track reviewed. Staff were devoting approximately 14 person days to managing this process and it was becoming increasingly difficult to meet the deadlines for preparing material for assessment panel meetings and processing results and feedback documents. However, teachers (and students) in the program had become convinced of the pedagogical benefits of such a rich and participatory assessment process and were reluctant to reduce its complexity and consequently the learning benefits for students.

\section{The role of technology in assessment:}

With the rise of social networking sites such as Facebook, students' expectations of on-line experiences have changed. For a time, BPM students were happy to upload their recordings using one part of the university learning management system, go to a different URL to listen to the work that was submitted, then go back to the course web site to provide feedback and so on. More

recently, students have found this experience to be very ' $20^{\text {th }}$ century,' something they thought of as 'an old person's idea of technology' and completely unsatisfactory by comparison with their social networking sites. This change in student perceptions meant that we needed to either simplify what was required of students (with a consequential loss of richness in the assessment process), or find a way of providing an on-line experience that was comparable with the rest of students' online lives. In an effort to address this issue, funding was sought from the host university to accommodate the entire assessment process on line, including almost all of the management tasks 
that had been so time-consuming previously. The proposal was accepted and the development of the Bachelor of Popular Music Assessment Tool (BoPMAT) was funded.

The BoPMAT engages students throughout the semester. Students can upload work-inprogress and receive feedback from teachers and peers at any time during the semester. All staff and students in the program can provide feedback directly to the system and the recipient of the feedback can rate each feedback response on a scale of one to five stars; the providers of feedback get feedback on the quality of their responses. At the end of the semester, students upload their completed tracks and the required associated written work directly to the BoPMAT and all submitted material is made available to all students and staff as soon as the submission period has closed. The system then allocates the submissions to assessment panels, ensuring an even spread of year levels for each panel. It also allocates students to assessment panels, following a number of rules that ensure no students will assess tracks that they have also submitted, and that there is a gender balance and even spread of year levels in each panel. Authorized members of staff can modify this initial allocation of submissions and panel members if necessary. Once the managers of the BoPMAT are happy with the composition of the panels, the system will display all necessary information about the panels including the members of each panel, what submissions they will assess, and the location and time for each panel meeting.

Panel members are able to begin their assessments at this point, and can enter feedback and marks directly to the BoPMAT. They can do this at their convenience and from wherever they wish. These provisional marks and comments will usually be modified in light of the discussions that will occur at the panel meetings and there will be further opportunity to modify BoPMAT entries up to 24 hours after the last assessment panel has met. Students are then able to see and rate the feedback and marks they have received, but the identity of the person providing the feedback is not visible to the students unless assessing students choose to include their names in their feedback comments. Teachers then assess the quality of each student's performance as an assessment panel member, provide feedback, and award a mark for this activity.

Considering the complexity of this process, there were remarkably few technical complications in the roll out of the BoPMAT. Most students were accustomed to the previous complex set of procedures and had come to value the outcomes in terms of the quantity and quality of the feedback they received. They were very forgiving of the initial 'teething problems' they encountered in the new system, and their feedback has been been overwhelmingly positive.

\section{Implications:}


It is difficult to overstate the positive impact of the BoPMAT on this process. In semester 2, 2010, 405 tracks were submitted by 104 students and 246,409 words of feedback were produced, an average of more than 2000 words of feedback for each student. More importantly, this feedback comes from a range of sources and represents a range of views. This provides a very important learning experience for students as they reconcile various opinions about their work, and the experience gained helps students develop an ability to provide well-framed feedback and to receive feedback graciously. Employers of graduates have identified this characteristic as a major asset in the workplace.

The correlation between marks produced by assessment panels as a whole and the marks awarded by the teacher panelist is very close, with a majority of marks being within one mark (out of 60 ) and $98 \%$ of marks within a range of four marks. This demonstrates that no student is significantly disadvantaged or advantaged by this marking process in comparison with the results they would have if teachers marked this work alone. The BPM program has been externally reviewed in 2006, 2008 and 2011. In each case, the pedagogical and assessment practices have been considered exemplary and graduate outcomes are rated as excellent.

\section{Conclusion:}

This technology has provided students with the opportunity to engage with a very complex assessment process in a context that matches their expectations of an on-line experience. It has enabled teachers to focus their attention on the provision of quality feedback to students rather than having to devote large amounts of time to the management of the process. Most importantly, it has enabled students to benefit from the experience of participating in assessment as assessors, enhancing their abilities to provide well founded and positively constructed feedback as well as enhancing their abilities to receive a range of feedback in a positive manner.

Development of the BoPMAT continues with a number of enhancements to the management interface in progress and it will then be made available for other activities within the Conservatorium. The next stage of development will include modification to deal with media types other than music files so it will be able to be used in a range of other contexts.

Technology plays an important role throughout the learning experiences of students in the BPM program. Among the most beneficial activities that utilise technology to a high degree is the student experience of technologically enhanced assessment of learning (through the marks they receive), assessment for learning (through the feedback they receive), and assessment as learning (through the learning they experience by acting as assessors). 


\section{References:}

Biggs, J. B. (1999). Teaching for quality learning at university: What the student does.

Philadelphia; Buckingham, England: Society for Research into Higher Education; Open University Press.

Biggs, J. B. (2008). Constructive Alignment. Retrieved October 25, 2010, from http://www.johnbiggs.com.au/constructive_alignment.html

Daniel, R. (2001). Self-Assessment in performance. British Journal of Music Education, 18, 215 226.

Green, L. (2001). How popular musicians learn: A way ahead for music education. Burlington, VT: Ashgate.

Green, L. (2006). Popular music education in and for itself, and for 'other' music: Current research in the classroom. International Journal of Music Education, 24, 101-118.

Green, L. (2008). Music, informal learning and the school: A new classroom pedagogy. Aldershot: Ashgate.

Lebler, D. (2007). Student-as-master? Reflections on a learning innovation in popular music pedagogy. International Journal of Music Education, 25, 205-221.

Lebler, D. (2008a). Perspectives on assessment in the learning of music. In D. Bennett \& M. Hannan (Eds.), Inside, Outside, Downside Up: Conservatoire Training and Musicians' Work (pp. 181-193). Perth: Black Swan Press.

Lebler, D. (2008b). Popular music pedagogy: Peer-learning in practice. Music Education Research, 10, 193-213.

Lebler, D. (2010, July 27-30). Informal learning in formal learning: Web 2 to the rescue. Paper presented at the Musician in Creative and Educational Spaces of the 21st Century [electronic resource]: Proceedings from the International Society for Music Education (ISME) 18th International seminar of the Commission for the Education of the Professional Musician, Shanghai Conservatory of Music.

Lebler, D., Burt-Perkins, R., \& Carey, G. (2009). What the students bring: Examining the attributes of commencing conservatoire students. International Journal of Music education: Research, 27, 232-249.

Siemens, G. (2005). Connectivism: Learning as network-creation. Retrieved from http://www.astd.org/LC/2005/1105_seimens.htm

Westerlund, H. (2006). Garage rock bands: A future model for developing musical expertise? International Journal of Music Education, 24, 119-125. 
Wiggins, G. P., \& McTighe, J. (2005). Understanding by Design. Alexandria, VA: ASCD.

Annotated bibliographies:

Musical Futures http://www.musicalfutures.org/

This web site introduces the conceptual basis and practices of the innovative Musical Futures project. The site includes many very useful resources that are freely available. Although this project has been developed in the UK, it has also been widely adopted in Australia.

\section{Learning Futures http://www.learningfutures.org/}

This web site includes information about an extension of the Musical Futures principles into other discipline areas. While not as established as the Musical Futures project, this site will be of use to those working in contexts other than music.

Youth Music Industries http://youthmusicindustries.com/

This web site contains information about a student-led initiative that is a co-curricular activity for music students at the Queensland Academy for the Creative Industries, a secondary school that follows the International Baccalaureate syllabus. It provides an illustration of the excellent outcomes that can be achieved by students acting collaboratively with significant but subtle teacher supervision and using a range of technologies to facilitate their project. 